Laporan Penelitian

\title{
Validitas dan reliabilitas kuesioner Nasal Obstruction Symptom Evaluation (NOSE) dalam Bahasa Indonesia
}

\author{
Windy Woro Paramyta*, Dini Widiarni*, Retno Sulistyo Wardani*, Adang Bachtiar** \\ *Departemen Telinga Hidung Tenggorok - Bedah Kepala Leher \\ Fakultas Kedokteran Universitas Indonesia/ Rumah Sakit Dr. Cipto Mangunkusumo \\ *Fakultas Kesehatan Masyarakat Universitas Indonesia \\ Jakarta
}

\begin{abstract}
ABSTRAK
Latar belakang: Sumbatan hidung merupakan keluhan yang sering didapatkan pada praktik Telinga Hidung Tenggorok sehari-hari. Penyebab sumbatan hidung adalah multifaktorial, dan dapat disebabkan oleh faktor struktural ataupun mukosa. Hidung tersumbat juga dapat mengakibatkan gangguan kualitas hidup seseorang. Pemeriksaan sumbatan hidung dapat dilakukan secara subjektif dan objektif. Pemeriksaan secara subjektif dapat dilakukan dengan menggunakan kuesioner Nasal Obstruction and Symptom Evaluation (NOSE). Kuesioner ini dapat digunakan untuk menilai sumbatan hidung akibat deformitas hidung seperti crooked nose, saddle nose, gangguan katup hidung dan deviasi septum. Tujuan: Penelitian ini dilakukan untuk menilai validitas dan reliabilitas kuesioner Nasal Obstruction and Symptom Evaluation (NOSE) dalam Bahasa Indonesia. Metode: Penelitian ini adalah penelitian studi potong lintang dengan desain deskriptif pada 62 responden. Hasil: Pada uji validitas didapatkan validitas internal yang baik pada seluruh pertanyaan, sedangkan uji reliabilitas kuesioner NOSE dengan adaptasi Bahasa Indonesia ini mempunyai nilai reliabilitas yang sangat baik dengan nilai Cronbach- $\alpha$ $>0,8$. Kesimpulan: Kuesioner NOSE dengan adaptasi Bahasa Indonesia adalah valid dan reliabel untuk menilai sumbatan hidung pada deformitas hidung.
\end{abstract}

Kata kunci: Nasal Obstruction Symptom Evaluation, sumbatan hidung, reliabilitas, validitas

\section{ABSTRACT}

Background: Nasal obstruction is one of the most common symptoms in daily ENT practice. Etiology of nasal obstruction is multifactorial and could be caused by mucosal or structural factors. Nasal obstruction also correlates with quality of life. There are subjective and objective evaluation to diagnose nasal obstruction. Subjective evaluation for nasal obstruction can be assessed by using Nasal Obstruction and Symptom Evaluation (NOSE) Questionnaire. This questionnaire could be used to assess nasal obstruction caused by nasal deformities such as crooked nose, saddle nose, nasal valve dysfunction and septal deviation. Purpose: To assess the validity and reliability of Nasal Obstruction and Symptom Evaluation (NOSE) Questionnaire in Bahasa Indonesia. Method: This study was a cross sectional descriptive study, involved 62 respondents. Result: Based on the validity of the test, it showed good internal validity of each question, while on reliability test of NOSE questionnaire was excellent with values of Cronbach- $\alpha>0.8$. Conclusion: The Indonesian adaptation of NOSE questionnaire was found as valid and reliable instrument for assessing nasal obstruction in nasal deformities.

Keywords: Nasal Obstruction Symptom Evaluation, nasal obstruction, reliability, validity

Alamat korespondensi: Dr. Windy Woro Paramyta. Departemen Telinga Hidung Tenggorok. Fakultas Kedokteran Universitas Indonesia, Rumah Sakit Dr. Cipto Mangunkusumo. 


\section{PENDAHULUAN}

Sumbatan hidung merupakan sensasi subjektif, akibat adanya perubahan fisiologis atau patologis, sehingga mengakibatkan menurunnya patensi hidung. Penyebab sumbatan hidung dapat dibagi menjadi komponen tetap yang membutuhkan perbaikan dengan operasi, dan komponen dinamis yang dapat dikontrol dengan terapi medikamentosa. Septum deviasi merupakan kelainan anatomi yang paling sering menimbulkan keluhan sumbatan hidung. ${ }^{1-4}$

Pasien dapat mengeluh adanya kongesti hidung, hidung tersumbat atau terasa penuh, serta berkurangnya kualitas tidur atau adanya kesulitan bernapas saat tidur. Anamnesis adanya rinitis alergi, rinosinusitis akut atau kronis, rinitis medikamentosa dan riwayat trauma juga perlu dilakukan. Pemeriksaan fisik meliputi pemeriksaan kavum nasi eksternal dan internal dengan rinoskopi anterior dan nasoendoskopi, yang perlu dilanjutkan dengan pemeriksaan ulang setelah penggunaan dekongestan. Berkurangnya sumbatan setelah penggunaan dekongestan mengindikasikan kemungkinan abnormalitas mukosa. ${ }^{3}$

Sumbatan hidung dapat diukur melalui penilaian subjektif dan objektif. Pengukuran subjektif didapatkan dari pasien dengan menggunakan kuesioner. Keuntungan penilaian subjektif ialah dapat menilai derajat sumbatan dari sudut pandang pasien. Terapi intervensi sering dilakukan untuk mengurangi keluhan subjektif, sehingga perlu digunakan parameter untuk menilai subjektivitas pasien. Parameter subjektif tersebut sebaiknya digunakan sebelum tindakan operatif, karena pasien dengan nilai yang tinggi akan mempunyai hasil pasca operasi yang lebih memuaskan. ${ }^{5}$

Saat ini terdapat banyak kuesioner kualitatif dan sistem standardisasi penilaian gejala yang telah dikembangkan dan divalidasi untuk mengevaluasi derajat sumbatan hidung dan efeknya terhadap kualitas hidup. Pengukuran ini dapat dilakukan menggunakan kuesioner yang sudah divalidasi seperti Visual Analogue Scale (VAS), Sinonasal Outcome Test (SNOT-22), dan Nasal Obstruction Symptom Evaluation (NOSE) score. Stewart $\mathrm{dkk}^{6}$ telah mengembangkan skala Nasal Obstruction Symptoms Evaluation (NOSE) sebagai perangkat standardisasi untuk penilaian gejala hidung tersumbat. Penilaian itu memperlihatkan bahwa gejala yang dirasakan pasien tidak selalu sama dengan pemeriksaan fisik yang ditemukan pemeriksa.

Saat ini dalam menilai sumbatan hidung secara subjektif belum ada kuesioner berbahasa Indonesia. Untuk itu perlu dilakukan penelitian mengenai validitas dan reliabilitas kuesioner NOSE pada deformitas hidung. Deformitas hidung yang akan dinilai pada penelitian ini adalah septum deviasi, gangguan katup hidung, crooked nose, dan saddle nose. Diharapkan setelah penelitian ini kuesioner NOSE dapat digunakan untuk menilai sumbatan akibat deformitas hidung.

\section{METODE}

Penelitian ini adalah penelitian deskriptif yang menggunakan rancangan potong lintang (cross-sectional). Penelitian ini dilakukan sejak Maret sampai Juni 2017. Percontoh penelitian ini adalah pasien dengan dan tanpa sumbatan hidung, baik dengan atau tanpa deformitas hidung di Poli Plastik Rekonstruksi dan Rinologi Departemen THTKL FKUI RSUPN Dr. Cipto Mangunkusumo. Cara pengambilan percontoh dengan cara consecutive dengan jumlah percontoh 62 orang, yaitu 52 pasien dengan deformitas hidung dan 10 pasien tanpa deformitas hidung.

\section{HASIL}

Tabel 1 menunjukkan bahwa deformitas hidung terbanyak pada pasien usia 16-30 
tahun (50\%), laki-laki (55,8\%), dan pada pasien dengan pendidikan S1 $(53,8 \%)$, dengan jenis deformitas hidung terbanyak adalah septum deviasi $(61,6 \%)$.

Dari tabel 4 dapat dilihat nilai $\mathrm{R}$ pada masing-masing pertanyaan. Uji validitas pada penelitian ini dilakukan dengan mengukur nilai $\mathrm{R}$ dari setiap pertanyaan yang kemudian akan dibandingkan dengan nilai $\mathrm{R}$ pada tingkat kemaknaan 0,05 untuk menilai validitas kuesioner. Nilai R setiap pertanyaan yang lebih tinggi menunjukkan bahwa pertanyaan tersebut valid.

Berdasakan uji reliabilitas yang dilakukan secara internal dengan menganalisis konsistensi butir-butir pertanyaan pada instrumen dengan menggunakan Cronbach- $\alpha$, didapati hasil reliabilitas NOSE pada penelitian ini adalah sebesar 0,846 .

\section{DISKUSI}

Pada penelitian ini didapatkan jumlah percontoh laki-laki lebih banyak daripada perempuan. Hal tersebut sesuai dengan teori bahwa deformitas hidung sering ditemukan pada laki-laki karena kasus trauma lebih sering terjadi pada laki-laki. Sebagian besar percontoh memiliki pendidikan Strata 1. Tingginya tingkat pendidikan membuat percontoh lebih memperhatikan adanya keluhan hidung tersumbat dan segera mencari pengobatan. Jenis deformitas yang terbanyak ditemukan pada penelitian ini adalah septum deviasi. Hal ini sesuai dengan kepustakaan yang mengatakan bahwa hampir $80 \%$ septum hidung manusia tidak lurus, dan hanya $20 \%$ dari septum deviasi tersebut yang menimbulkan sumbatan. Deviasi septum juga sering menyebabkan deformitas hidung

Tabel 1. Karakteristik percontoh

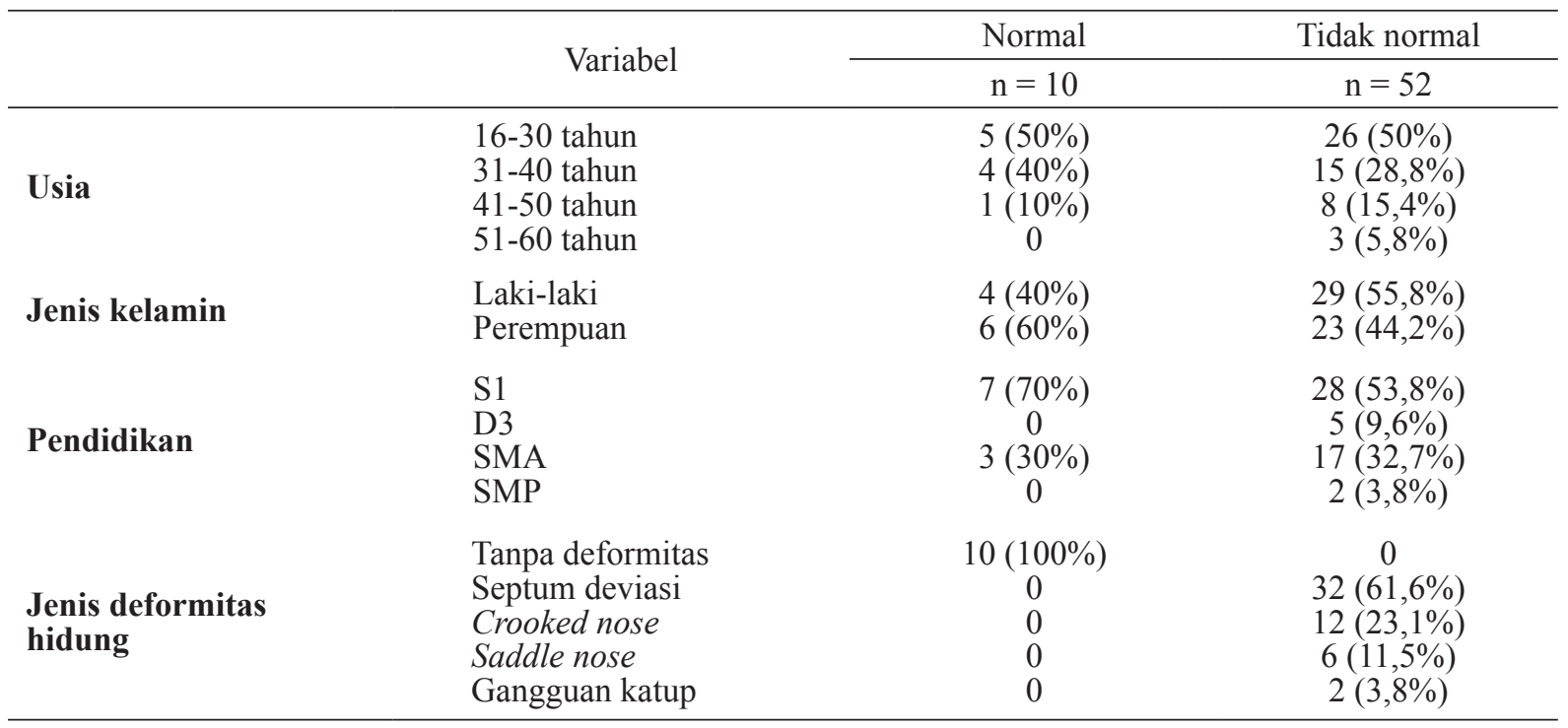

Tabel 2. Versi asli kuesioner Nasal Obstruction Symptom Evaluation (NOSE)

\begin{tabular}{|c|c|c|c|c|c|c|}
\hline & & $\begin{array}{l}\text { Not a } \\
\text { problem }\end{array}$ & $\begin{array}{l}\text { Very mild } \\
\text { problem }\end{array}$ & $\begin{array}{l}\text { Moderate } \\
\text { problem }\end{array}$ & $\begin{array}{l}\text { Fairly bad } \\
\text { problem }\end{array}$ & $\begin{array}{l}\text { Severe } \\
\text { problem }\end{array}$ \\
\hline 1. & Nasal congestion or stuffiness & 0 & 1 & 2 & 3 & 4 \\
\hline 2 . & Nasal blockage or obstruction & 0 & 1 & 2 & 3 & 4 \\
\hline 3 . & Trouble breathing through my nose & 0 & 1 & 2 & 3 & 4 \\
\hline $\begin{array}{l}4 . \\
5\end{array}$ & $\begin{array}{l}\text { Trouble sleeping } \\
\text { Unable to get enough air through mv }\end{array}$ & 0 & 1 & 2 & 3 & 4 \\
\hline & nose during exercise or exertion & 0 & 1 & 2 & 3 & 4 \\
\hline
\end{tabular}


abel 3. Kuesioner NOSE bahasa Indonesia

\begin{tabular}{llcccc}
\hline & $\begin{array}{c}\text { Tidak } \\
\text { bermasalah }\end{array}$ & $\begin{array}{c}\text { Sedikit } \\
\text { bermasalah }\end{array}$ & $\begin{array}{c}\text { Agak } \\
\text { bermasalah }\end{array}$ & $\begin{array}{c}\text { Cukup } \\
\text { bermasalah }\end{array}$ & $\begin{array}{c}\text { Sangat } \\
\text { bermasalah }\end{array}$ \\
\hline 1. $\begin{array}{l}\text { Hidung tersumbat yang hilang } \\
\text { timbul sesuai dengan perubahan }\end{array}$ & 0 & 1 & 2 & 3 & 4 \\
$\begin{array}{l}\text { posisi kepala, cuaca atau suhu } \\
\text { Hidung tersumbat yang menetap } \\
\text { terutama pada salah satu sisi hidung }\end{array}$ & 0 & 1 & 2 & 3 & 4 \\
$\begin{array}{l}\text { yang lebih dominan } \\
\text { Kesulitan bernapas lewat hidung }\end{array}$ & 0 & 1 & 2 & 3 & 4 \\
4. Kesulitan tidur mapat cukup udara \\
5.
\end{tabular}

Tabel 4. Uji validitas kuesioner NOSE

\begin{tabular}{ll}
\hline Variabel & $\mathrm{R}$ \\
\hline & \\
Pertanyaan 1 & 0,377 \\
Pertanyaan 2 & 0,808 \\
Pertanyaan 3 & 0,816 \\
Pertanyaan 4 & 0,594 \\
Pertanyaan 5 & 0,702 \\
\hline
\end{tabular}

*Nilai R pada tingkat kemaknaan 0,05 sebesar 0,25

eksternal yang akan menyebabkan perubahan bentuk dan fungsi hidung. Deformitas eksternal hidung dapat terjadi karena defek pada piramid hidung, kartilago, deformitas septum atau kombinasi dari faktor tersebut. ${ }^{7}$

Penelitian ini diawali dengan permohonan izin secara tertulis untuk melakukan proses validasi kepada pemilik hak cipta NOSE yakni dr. Michael G. Steward di Houston, Amerika Serikat melalui American Academy of Otolaryngology-Head and Neck Surgery Foundation. Penelitian dilakukan setelah mendapat perizinan mengenai validasi NOSE tersebut. Kuesioner NOSE diterjemahkan ke dalam bahasa Indonesia oleh ahli bahasa dari Lembaga Bahasa Universitas Indonesia.

Hasil diskusi oleh komite yang terdiri dari peneliti dan pembimbing pada sidang usulan penelitian didapatkan kesulitan pemahaman pada beberapa pertanyaan, sehingga dilakukan beberapa perubahan kalimat yakni: 1) pada pertanyaan pertama "kongesti hidung atau hidung tersumbat"; 2) pertanyaan kedua "obstruksi hidung atau sumbatan hidung”.

Kalimat di atas diubah menjadi: 1) "hidung tersumbat yang hilang timbul sesuai dengan perubahan posisi kepala, cuaca atau suhu"; 2) "hidung tersumbat yang menetap terutama pada salah satu sisi hidung yang lebih dominan".

Uji validitas pada penelitian ini digunakan dengan membandingkan nilai antara masingmasing pertanyaan dengan nilai pada tingkat kemaknaan 0,05 . Nilai pada tingkat kemaknaan 0,05 adalah 0,25 , sementara nilai masing-masing pertanyaan lebih besar dari 0,25. Hal tersebut menunjukkan bahwa masing-masing pertanyaan pada kuesioner NOSE tersebut adalah valid.

Uji reliabilitas pada kuesioner NOSE dengan menggunakan Cronbach- $\alpha$ adalah sebesar 0,846. Djemari ${ }^{8}$ mengatakan suatu penelitian dikatakan reliabel apabila memiliki nilai alpha minimal 0,7. Menurut George dan Mallery, seperti yang dikutip Gliem ${ }^{9}$ yakni apabila nilai Cronbach- $\alpha>0,7$ berarti hasil penilaian diterima, nilai $>0,8$, mempunyai nilai yang baik dan nilai $>0,9$ dengan hasil uji yang sangat baik. Kuesioner NOSE ini dengan demikian dapat dikatakan mempunyai reliabilitas yang baik. 
Kuesioner NOSE memiliki nilai 0-4 pada masing-masing pertanyaan, total dari seluruh pertanyaan tersebut akan dikalikan dengan 5 sehingga didapatkan total nilai 0-100, dengan nilai 0 adalah tidak ada sumbatan hidung, 5-25 adalah sumbatan hidung ringan, 30-50 sedang, 55-75 berat dan sangat berat apabila $>80 .{ }^{10}$

\section{DAFTAR PUSTAKA}

1. Keeler J, Most SP. Measuring nasal obstruction, nasal airway rhinomanometry, nasal resistance, nasal function. Facial Plast Surg Clin NA. 2016; 24(3):315-322.

2. Pallanch J, Jorissen M. Nasal function. In: Flint PW, Haughey BH, Lund VJ, Niparko JK, Richardson MA, Robbins KT, et al, editors. Cummings Otolaryngology Head \& Neck Surgery. 5th ed: Mosby; 2010. p. 644-57.

3. Zahedi FD, Husain S, Gendeh BS. Functional outcome evaluation of septorhinoplasty for nasal obstruction. Indian J Otolaryngol Head Neck Surg. 2016; 68(2):218-223.

4. Clement PAR, Halewyck S, Gordts F, Michel O. Critical evaluation of different objective techniques of nasal airway assessment: a clinical review. Eur Arch Otorhinolaryngol. 2014; 271(10):26172625.

5. Leung RM, Walsh WE, Kern RC. Sinonasal anatomy and physiology. In: Ferguson BJ, Ryan MW, eds. Bailey's Head and Neck Surgery Otolaryngology. 5th ed. Philadephia: Lippincott Williams \& Wilkins; 2014: 359-369.
Dari hasil penelitian ini didapatkan bahwa kuesioner NOSE memiliki validitas dan reliabilitas yang baik dan dapat digunakan untuk menilai sumbatan hidung pada pasien dengan deformitas hidung. Pemeriksaan subjektif dalam menilai sumbatan hidung akan lebih baik dikonfirmasi dengan pemeriksaan objektif berupa rinomanometri.

6. Stewart MG, Witsell DL, Smith TL, Weaver EM, Yueh B, et al. Development and validation of the nasal obstruction symptom evaluation (NOSE) scale. Otolaryngol Head Neck Surg. 2004;130(February):157-163.

7. Tardy M. Nasal reconstruction and rhinoplasty. In: Snow J, Ballenger J, eds. Ballenger's Otorhinolaryngology Head and Neck Surgery. 16th edition. Spain: BC Decker; 2003:842-899.

8. Djemari M, Wahyu W. Komparasi ketepatan estimasi koefisien reliabilitas teori skor murni klasik. 2012. Available from: http// widhiarso.staff.ugm.ac.id.

9. Gliem JA, Gliem RR. Calculating, interpreting, and reporting Cronbach's alpha reliability coefficient for Likert-Type Scales. 82-88. Presented at the Midwest Research-to-Practice Conference in Adult, Continuing, and Community Education, The Ohio St. 2003.

10. Lipan M, Most S. Development of a severity classification system for subjective nasal obstruction. JAMA Facial Plastic Surgery. 2013; 15(5): 358-62. 